\title{
Some, but not all of the premenstrual syndrome symptoms affect the medical exam scores in medical students
}

\author{
Filiz Bilir ${ }^{1}$, Ramazan Akdemir ${ }^{2}$, Cemil Bilir
}

\begin{abstract}
Objectives: This research aims to identify the effects of premenstrual syndrome (PMS) symptoms on the school exam scores in medical students.

Methods: This cross-sectional study was designed at Sakarya University School of Medicine The study included medical students who were in the first, second, and third year of class. In this study, there were 193 male and 100 female students. The study investigated how PMS symptoms affected medical student's exam scores and school success. All exam scores were recorded during the two-consecutive semester so duration of study was one year

Results: There were 100 female students, and they had five different committee exams for one year. Female student's exam scores were significantly higher for four committees and an average score of all year. The mean age of female students was $19.9 \pm 1.5$. Acne, nausea/vomiting, sleeping, abdominal bloating, and prurience change had significantly different exam scores compared to the group without these symptoms. Students with acne had substantially higher exam scores than without acne; inversely, the other four symptoms negatively affected exam scores.

Conclusion: Some of the PMS symptoms can be more annoying and should change the quality of life more than the other symptoms, so we should define these symptoms to improve our student's quality of life and school success.
\end{abstract}

KEYWORDS: Premenstrual syndrome symptoms, Medical students, Exam scores.

How to cite this:

doi: https://doi.org/10.12669/pjms.37.4.3931

Bilir $F$, Akdemir R, Bilir $C$. Some, but not all of the premenstrual syndrome symptoms affect the medical exam scores in medical students. Pak J Med Sci. 2021;37(4):1190-1195. doi: https://doi.org/10.12669/pjms.37.4.3931

This is an Open Access article distributed under the terms of the Creative Commons Attribution License (http://creativecommons.org/licenses/by/3.0), which permits unrestricted use, distribution, and reproduction in any medium, provided the original work is properly cited.

1. Filiz Bilir,

Department of Medical Education,

2. Ramazan Akdemir,

Department of Cardiology and Medical Education,

3. Cemil Bilir

Department of Internal Medicine,

1-3: Sakarya University School of Medicine,

Sakarya, Turkey.

Correspondence:

Filiz Bilir M.D.

Department of Medical Education,

Sakarya University School of Medicine,

Street Name \& Number: 32 Evler mh 822 sk. NO D5

Serdivan, Sakarya - Turkey.

E-mail: drflzyldz@hotmail.com

* Received for Publication:

November 16, 2020

* Revision Received:

* Revision Accepted:
March 1, 2021

March 19, 2021

\section{INTRODUCTION}

Menstrual cycle has two main phases, one is an ovarian cycle, and the second one is uterine cycle. In the ovarian cycle there are two phases and first one is estrogen dominant called as follicular phase and the second is progesterone dominant period called as luteal phase. These hormonal changes should effect women metabolism as well as quality of life. ${ }^{1}$

Premenstrual syndrome (PMS) is defined as a woman in reproductive age. It has emotional or physical symptoms that start a couple of days before the menses, ameliorate after the menstrual 


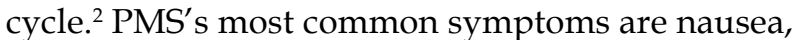
vomiting, thirsty, vertigo, depression, mood changes, dizziness, flatulence, mastalgia, crying, fatigue, irritability, anxiety, low concentration, and forgetfulness, appetite changes, gastrointestinal symptoms, and edema. ${ }^{3}$ Indeed there are no exact criteria for the diagnosis because of the subjectivity of PMS symptoms, ambiguous complaints, and psychological components of these symptoms make the diagnosis hard. Determining the symptoms time and at least one effective symptom with one somatic symptom, which causes a dysfunction in work, education, or social performance are essential. ${ }^{4}$ Therefore, criteria of the American College of Obstetricians and Gynecologists' are used for diagnosis. ${ }^{5}$ The physical and emotional symptoms in PMS can decrease women's quality of life (QOL), but there are conflicting results with the effect of PMS symptoms on QOL. ${ }^{6,7}$

PMS affects regular activities and social skills and quality of life and social skills. ${ }^{8}$ Also, the severity of PMS symptoms can change with their duration and progress to the Premenstrual dysphoric disorder (PMDD); additionally, these menstrual changes, particularly in the luteal phase, are related to many cognitive, psychological, and behavioral changes. ${ }^{9}$ PMS and PMDD affect reproductive ages, socially and psychologically active adults, but we don't know how these findings influence academic performance. Limited data about academic life have been presented previously and most of them had investigated the relationship between quality of life and PMS or PMDD. In a Brazil study included 642 students that found $49.9 \%$ of PMS and $23.3 \%$ of PMDD prevalence in addition they found close relation with lower quality of life and severity of PMS symptoms. However, a study published by Antunes et al. included university students in the same population did not find decreased PMDD symptoms in students who were using combined oral contraceptive pills. ${ }^{10,11}$ On the other hand it is well known that students with good physical health have better academic performance but, there is no data about medical students who had PMS symptoms and their exam scores. ${ }^{12}$ That's why this study aimed to investigate the possible relationship between PMS symptoms and the medical students' exam success.

\section{METHODS}

This cross-sectional study was designed at Sakarya University School of Medicine after the approval of the local ethical committee (Ref:
71522473/050.01.04/135, Dated: 07/05/2019). The study included medical students who were in the first, second, and third year of class. Between the two semesters, all medical student exams scores were recorded. They completed five different exams during the two semesters so duration of study was one year. A gynecologist and obstetrician researcher examined and then filled the students' data such as abdominal ultrasound findings, medications history, physical or emotional complaints and exam scores during their free time and the PMS form. Participation in the study was voluntary.

Inclusion criteria: It included PMS symptoms for instance prurience, anxiety, irritability, depression symptoms, social withdrawal, tenderness of breast, abdominal bloating, headache, edema in addition to PMS symptoms also normal abdominal ultrasound findings, and normal ovulatory functions were the other inclusion criteria.

Exclusion criteria: Amenorrhea, endometriosis, pregnancy, and chronic disease, causing abdominal pain, using oral contraceptive drugs or IUD, and students with adnexal mass or myoma uteri USG. The demographic form questions included lifestyle and reproductive variables, economic status, age, smoking history, and menstrual characteristics. The symptom dates were constructed based on ACOG PMS criteria, which included behavioral and somatic symptoms as mentioned above. The diagnosis was accepted as PMS if a female student had at least one mood and one physical symptom.

All data analyses were done with SPSS version 18.0 (SPSS Inc., Chicago, IL). Descriptive statistics described the sample and main variables such as means and standard deviation, and frequency. Qualitative variables were analyzed with the chi-square test and quantitative data with the Student t-test. Spearman's rho correlation was used to define the relationship between the variables. Regression analysis used for exploring the predictability of students' exam scores based on different variables and P-values lower than 0.05 was considered statistically significant.

\section{RESULTS}

In this study, there were 193 male and 100 female students. In one year, students had five different committee exams, and we compared five of these exams and average scores, both male and female 
Table-I: Male and Female Exam Scores.

\begin{tabular}{lccc}
\hline Exam Score & Male (SD) & Female (SD) & P value \\
\hline 1st committee & $65.9(13)$ & $70.2(11)$ & 0.007 \\
2nd committee & $61.7(19)$ & $67.4(12)$ & 0.015 \\
3rd committee & $66.3(16)$ & $71.3(14)$ & 0.008 \\
4th committee & $66.1(17)$ & $73.5(13)$ & 0.0001 \\
5th committee & $71.8(16)$ & $75(16)$ & 0.058 \\
Average score & $67.3(14)$ & $73(13.7)$ & 0.001 \\
\hline
\end{tabular}

(Table-I). Female student's exam scores were significantly higher for four committees and the average score of all year. The mean age of female students was $19.9 \pm 1.5$, body mass index was 22 , and weight was 58,9. We examined 20 different complaints or symptoms with a questionnaire and physical examination and summarized in Fig.1. The most common four findings were acne, abdominal bloating, anxiety, and irritability.

Acne, nausea/vomiting, sleeping, abdominal bloating, and prurience change had significantly different exam scores compared to the group without these symptoms. Abdominal bloating was one of the most common symptoms of our study population. Seventy-four students had abdominal bloating, and the remaining $26 \mathrm{did}$ not besides the average exam scores were 71.6 vs. 77 , respectively $(\mathrm{p}<0.05)$. Also $3^{\text {rd }}, 4^{\text {th }}$ and $5^{\text {th }}$ committee scores were significantly lower in students who had abdominal bloating (69.5 vs 76.3 with P-value $0.03,72$ vs 77.8 with P-value 0.05 and 73 vs 81.7 with P-value 0.018 , respectively). Acne is the $4^{\text {th }}$ most common symptom; Seventy-four students had acne and 26 did not. Exam scores was 74.8 in the group who had acne and it was 68.9 in the group who did not have acne and it was statically significant $(p<0.05)$. According to the end-of-year average exam scores sleepy and nausea/vomiting were the other two significant factors that affect the exam scores. Students who were sleepy had significantly lower exam scores as well as nausea/vomiting, 69 vs. 75, and 65 vs. 74, respectively. All significant values are presented in Table-II.

\section{DISCUSSION}

In this study, we found that five of the PMS sign and symptoms such as acne, nausea/ vomiting, changes in sleep pattern, abdominal bloating, and change of prurience affected the school exam scores and academic performance. Symptoms included nausea/vomiting, change in sleep pattern, abdominal bloating, and change of prurience caused lower exam scores than without these symptoms on the other hand

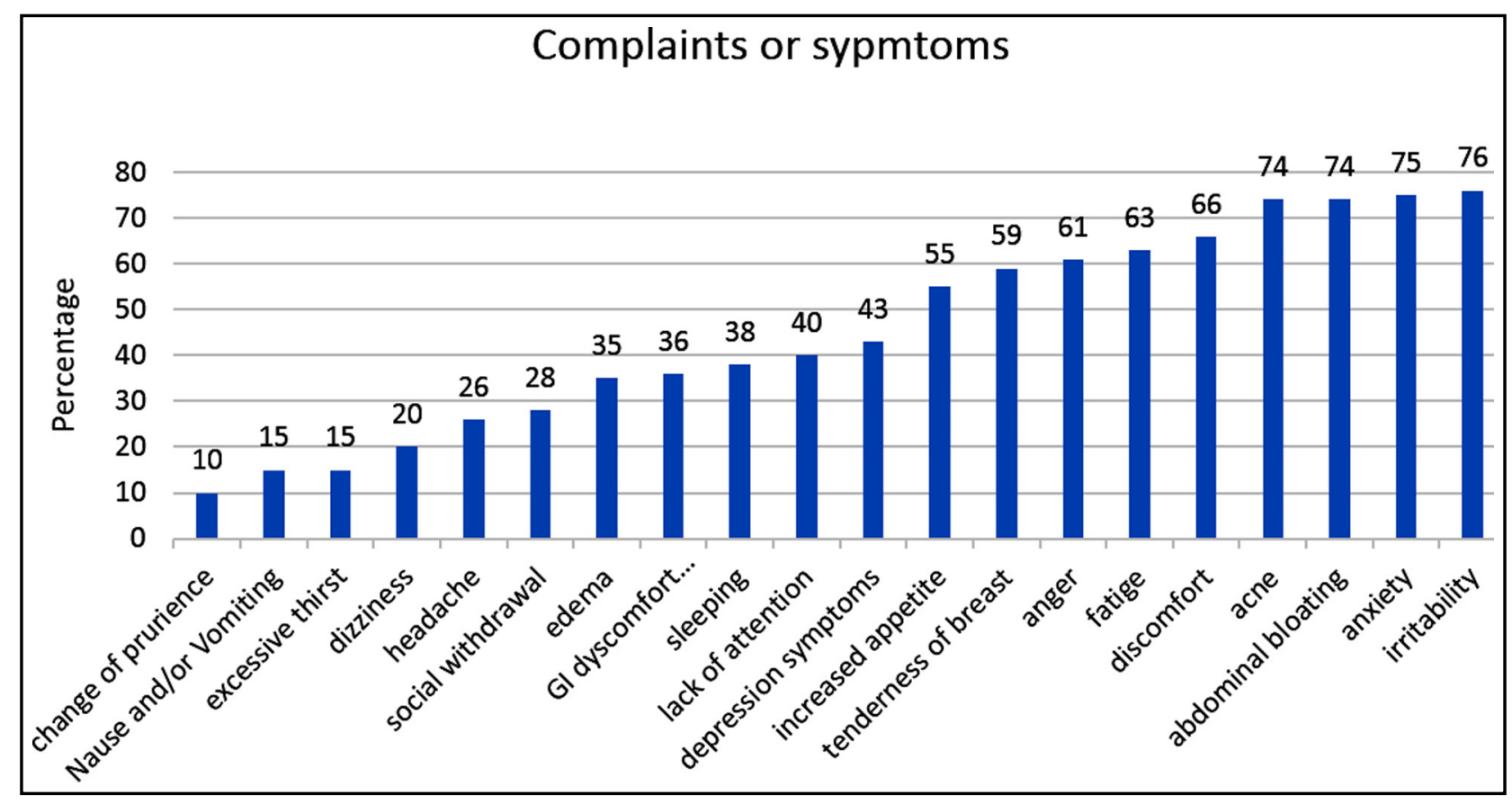

Fig.1: Percentage of each symptom or complaint in female students. 
Filiz Bilir et al.

Table-II: Exam scores and premenstrual syndrome symptoms.

\begin{tabular}{|c|c|c|c|c|c|}
\hline Exam & $\begin{array}{l}\text { Acne } \\
\text { Yes/no }\end{array}$ & $\begin{array}{c}\text { Nause/ } \\
\text { vomiting } \\
\text { Yes/no }\end{array}$ & $\begin{array}{c}\text { Abd.bloating } \\
\text { Yes/no }\end{array}$ & $\begin{array}{l}\text { Sleeping } \\
\text { Yes/no }\end{array}$ & $\begin{array}{c}\text { Change of } \\
\text { prurience } \\
\text { Yes/no }\end{array}$ \\
\hline 1st Committee & $\begin{array}{l}72 \text { vs } 64 \\
\text { P:0.003 }\end{array}$ & $\begin{array}{c}64.9 \text { vs } 71 \\
P: 0.052\end{array}$ & $\begin{array}{c}70 \text { vs } 70 \\
\text { P:0.9 }\end{array}$ & $\begin{array}{c}68 \text { vs } 71.6 \\
P: 0.12\end{array}$ & $\begin{array}{c}62 \text { vs } 71 \\
P: 0.018\end{array}$ \\
\hline 2nd Committee & $\begin{array}{c}68 \text { vs } 62 \\
P: 0.08\end{array}$ & $\begin{array}{c}62 \text { vs } 68 \\
\text { P:0.2 }\end{array}$ & $\begin{array}{c}66 \text { vs } 70.8 \\
\text { P: } 0.17\end{array}$ & $\begin{array}{c}64 \text { vs } 68.8 \\
\text { P:0.2 }\end{array}$ & $\begin{array}{c}59 \text { vs } 68 \\
\text { P:0.08 }\end{array}$ \\
\hline 3rd Committee & $\begin{array}{c}72 \text { vs } 68 \\
\text { P:0.22 }\end{array}$ & $\begin{array}{c}61 \text { vs } 73 \\
P: 0.004\end{array}$ & $\begin{array}{c}69.5 \text { vs } 76 \\
P: 0.033\end{array}$ & $\begin{array}{c}68 \text { vs } 73 \\
\text { P:0.07 }\end{array}$ & $\begin{array}{c}61.9 \text { vs } 72 \\
\text { P:0.026 }\end{array}$ \\
\hline 4th Committee & $\begin{array}{l}75 \text { vs } 68 \\
P: 0.032\end{array}$ & $\begin{array}{c}79 \text { vs } 77 \\
\text { P:0.2 }\end{array}$ & $\begin{array}{c}72 \text { vs } 77.8 \\
P: 0.054\end{array}$ & $\begin{array}{c}69 \text { vs } 75.9 \\
P: 0.019\end{array}$ & $\begin{array}{c}65 \text { vs } 74 \\
\text { P:0.04 }\end{array}$ \\
\hline 5th Committee & $\begin{array}{c}77 \text { vs } 70 \\
\text { P:0.03 }\end{array}$ & $\begin{array}{l}64 \text { vs } 77 \\
P: 0.003\end{array}$ & $\begin{array}{c}73 \text { vs } 81 \\
\text { P:0.018 }\end{array}$ & $\begin{array}{c}70 \text { vs } 78.7 \\
\text { P:0.01 }\end{array}$ & $\begin{array}{c}72 \text { vs } 75.9 \\
\text { P:0.5 }\end{array}$ \\
\hline Average Score & $\begin{array}{l}74 \text { vs } 67 \\
\text { P:0.012 }\end{array}$ & $\begin{array}{c}65 \text { vs } 74 \\
P: 0.009\end{array}$ & $\begin{array}{c}71 \text { vs } 77 \\
\text { P:0.048 }\end{array}$ & $\begin{array}{c}69 \text { vs } 75 \\
P: 0.016\end{array}$ & $\begin{array}{c}66 \text { vs } 73 \\
\text { P:0.07 }\end{array}$ \\
\hline
\end{tabular}

students who had acne had higher exam scores. This is the first study that investigated how PMS symptoms affect the academic performance of medical students.

The prevalence of PMS in the Turkish population was reported between the ranges of $6.1 \%-91.8 \%$. This prevalence can be changed according to age or population characteristics; for example, it was $37 \%$ in nursing students and $72 \%$ in medical school students. ${ }^{13,14}$ All these studies have focused on severity of symptoms and effects on quality of life however they did not investigated the academic success or how those symptoms change school life. Also, different population studies showed a broad range of $24 \%-100 \% .{ }^{15,16}$ Furthermore, only a few studies on medical students found a variation in PMS prevalence, roughly 90\% in Egypt with ICD-10 criteria, 35\% in Saudi Arabia used the ACOG criteria, and $51 \%$ in Pakistan according to ICD-10. ${ }^{17,18}$ Our results are also concordant with the literature and the PMS prevalence was around $60 \%$. Goker et al. found the most common symptom was abdominal bloating with $88 \%$ and irritability as an emotional symptom around $88 \% .^{7}$ A different population study, which included Nigerian university students published by Adewuya et al., showed that breast tenderness was $35.5 \%$. A second study found that breast tenderness was the most frequent symptom in Lebanese medical students, and the rate was $65 \% . .^{3,9,19}$ Similar to these results, our study found abdominal bloating, anxiety, and irritability were the three most common symptoms, and breast tenderness was around $60 \%$.

We also know that younger women have more severe and significantly more symptoms, so this can explain why PMS decreased the quality of life in younger ages. ${ }^{19}$ More than $70 \%$ of students had at least one PMS symptom in our study, but until this study, we did not know which symptoms can significantly affect the quality of life, especially medical students. A study showed a significant correlation between the general health score SF-36 with PMS and severe PMS patients had the lowest SF-36 scores. In the same study, the authors found that the lowest mean SF-36 score was correlated with emotional functions (Social withdrawal, angry outbursts, anxiety, and depression) in the severe PMS group. ${ }^{7}$ Taghizadeh et al. found that "the more the severity of PMS, the less the quality of life in mental health," and it can cause depression, nervousness, and sadness. ${ }^{20}$ Nisar et al. investigated PMS in medical students. They found that quality of life score was significantly lower in the PMS, and many symptoms such as emotional problems, physical problems, vitality, mental health, and body pain significantly differ. SF-36 scores were significantly lower in the group who had PMS compared to those without PMS. ${ }^{17}$ One of the studies investigated PMS symptoms on how to affect the quality of life, even they found significant deterioration of quality of life, 
but they did not explore the school success or exam scores of students. Our study compared 20 different symptoms with exam scores, and only four of them were significantly different for the end of year scores. Students who had acne had significantly higher exam scores, especially the first, $4^{\text {th }}$ and $5^{\text {th }}$ committee and the end of the year exam score. On the other hand, the other four symptoms, nausea/vomiting, change in sleep pattern, abdominal bloating, change of prurience affect negatively, and students who had these four symptoms had significantly lower exam scores.

A Turkish college student study revealed that the PMS rate was $72 \%$ in college students, which adversely affects the quality of life, especially in the physical, mental, and environmental fields. Also, an Iranian study was carried out in medical students; authors found that mental health and environmental symptoms were significantly different in students who had severe PMS compared to without PMS symptoms. ${ }^{21,22}$ To our knowledge, our research is the first study that investigated what kind of PMS symptoms affect the quality of life in medical students in the field of school success. Hussein Shehadeh et al. investigated university students' academic performance as GPA scores in premenstrual syndrome and premenstrual dysphoric disorder, and there was no significant difference between the groups. Still, they found that PMS prevalence was $92.3 \%$, and PMDD was $7.7 \%$ among female university students. ${ }^{23}$ On the other hand, a different study investigated the PMS and exam scores in female university students. Like the previous research, they did not find a difference between the group with and without PMS student's exam scores. Students who had a longer duration of menses ( $<21$ days vs. 21-35 days vs. $>35$ days) had significantly lower exam scores. ${ }^{24}$ This finding has not reverberated to our results, but a longer menses period can decrease the study time, so that's why they had lower exam scores.

During the follicular phase, estrogen begins to increase and it can affect the brain functions and change the female's affective and cognitive status so that these interactions can be responsible for mood changes and cognitive functions. Therefore, fluctuating mood and cognitive skills can be a reason for these hormonal changes, especially in estrogen surge. Even we cannot say the exact mechanism of our results, we can speculate this, increasing serum testosterone levels should be related to premenstrual acne, and testosterone has neuroprotective effects. It can improve memory and verbal learning. ${ }^{25}$ In our study, students with acne had significantly higher exam scores. Students with decreased prurience had lower exam scores; these two clinical findings can be related to the fluctuation of serum testosterone levels during the menses. The treatment of these symptoms should increase students' quality of life and may improve our female student's academic success.

Limitations of the Study: We included students who had PMS symptoms, not focused on PMS diagnosis, so some of the students could diagnose PMS and PMS symptoms. Additionally, many other reasons could affect the exam scores, and to exclude these factors, we compared the exam scores with males and females.

\section{CONCLUSION}

In conclusion, some of the PMS symptoms had a higher clinical impact. They can change the quality of life more than the other symptoms. If we define these symptoms clearly, such as acne has a positive effect, nausea/vomiting, change in sleep pattern, abdominal bloating, and change of prurience has a negative impact.

Note: The study participants given their written informed consent and that the study protocol was approved by the institute's committee on human research.

\section{Conflicts of interest: None}

Fund: None

\section{REFERENCES}

1. Klump KL, Keel PK, Racine SE, Burt AA, Neale M, Sisk CL, et al. The interactive effects of estrogen and progesterone on changes in emotional eating across the menstrual cycle. J Abnorm Psychol. 2013;122(1):131-137. doi: $10.1037 / a 0029524$

2. O'Brien PMS, Bäckström T, Brown C, Dennerstein L, Endicott J, Epperson CN, et al. Towards a consensus on diagnostic criteria, measurement and trial design of the premenstrual disorders: The ISPMD Montreal consensus. Arch Womens Ment Health. 2011;14(1):13-21. doi: 10.1007/s00737-010-0201-3

3. Adewuya AO, Loto OM, Adewumi TA. Pattern and correlates of premenstrual symptomatology amongst Nigerian University students. J Psychosomat Obstet Gynaecol. 2009;30:127-132. doi: 10.1080/01674820802545446 
4. Isik H, Ergol S, Aynioglu O, Sahbaz A, Kuzu A, Uzun M. Premenstrual syndrome and life quality in Turkish health science students. Turk J Med Sci. 2016;46:695-701. doi: 10.3906/sag-1504-140

5. Balaha MH, Amr MAEM, Al Moghannum MS, Al Muhaidab NS. The phenomenology of premenstrual syndrome in female medical students: A cross sectional study. Pan Afr Med J. 2010;5:4. doi: 10.4314/pamj.v5i1.56194

6. Braverman PK. Premenstrual Syndrome and Premenstrual Dysphoric Disorder. J Pediatr Adol Gynec. 2007;20:3-12. doi: 10.1016/j.jpag.2006.10.007

7. Goker A, Artunc-Ulkumen B, Aktenk F, Ikiz N. Premenstrual syndrome in Turkish medical students and their quality of life. J Obstet Gynaecol. 2014;35(3):275-278. doi: 10.3109/01443615.2014.948820

8. Derman O, Kanbur NO, Tokur TE, Kutluk T. Premenstrual syndrome and associated symptoms in adolescent girls. Eur J Obstet, Gynecol Reproduct Biol. 2004;116:201-206. doi: 10.1016/j.ejogrb.2004.04.021

9. Direkvand-Moghadam A, Sayehmiri K, Delpisheh A, Satar K. Epidemiology of premenstrual syndrome, a systematic review and meta-analysis study. J Clin Diagn Res. 2014;8:106e9. doi: 10.7860/JCDR/2014/8024.4021

10. Figueira Victor F, Souza AI, Danúbia C, Barreiros T, Nunes De Barros JL, Carvalho Da Silva FA, et al. Quality of Life among University Students with Premenstrual Syndrome Qualidade de vida entre estudantes universitárias com síndrome pré-mesntrual. Rev Bras Ginecol Obstet. 2019;41:312-317. doi: 10.1055/s-0039-1688709

11. Antunes G, Rico VV, Gouveia Jr. A. Variações da ansiedade relatada em função do ciclo menstrual e do uso de pílulas anticoncepcionais. Interação em Psicologia. 2004;8(1):81-87.

12. Sarwar S, Aleem A, Nadeem MA. Health related quality of life (Hrqol) and its correlation with academic performance of medical students. Pak J Med Sci. 2019;35(1):266-270. doi: 10.12669 / pjms.35.1.147

13. Derman O, Kanbur NO, Tokur TE, Kutluk T. Premenstrual syndrome and associated symptoms in adolescent girls. Eur J Obstet Gynecol Reproduct Biol. 2004;116:201-206. doi: 10.1016/j.ejogrb.2004.04.021

14. Delara M, Ghofranipour F, Azadfallah P, Tavafian SS, Kazemnejad A, Montazeri A. Health related quality of life among adolescents with premenstrual disorders: A cross sectional study. Health Qual Life Outcomes. 2012;10:1. doi: 10.1186/1477-7525-10-1

15. Sadler C, Smith H, Hammond J, Bayly R, Borland S, Panay N, et al. Lifestyle factors, hormonal contraception, and premenstrual symptoms: The United Kingdom Southampton women's survey. J Women's Health (Larchmont). 2010;19:391-396. doi: 10.1089/jwh.2008.1210

16. Vichnin $M$, Freeman EW, Lin $H$, Hillman J, Bui S. Premenstrual Syndrome (PMS) in Adolescents: Severity and Impairment. J Pediat Adolesc Gynecol. 2006;19:397402. doi: 10.1016/j.jpag.2006.06.015
17. Nisar N, Zehra N, Haider G, Munir AA, Sohoo NA. Frequency, intensity and impact of premenstrual syndrome in medical students. J Coll Physicians Surg Pak. 2008;18:481-484. doi: 08.2008/JCPSP.48148484

18. Nooh AM, Abdul-Hady A, El-Attar N. Nature and Prevalence of Menstrual Disorders among Teenage Female Students at Zagazig University, Zagazig, Egypt. J Pediatr Adolesc Gynecol. 2016;29(2):137-142. doi: 10.1016/j. jpag.2015.08.008

19. Bakhshani NM, Mousavi MN, Khodabandeh G. Prevalence and severity of premenstrual sympto ms among Iranian female university students. J Pak Med Assoc. 2009;59:205-208.

20. Taghizadeh Z, Shirmohammadi M, Feizi A, Arbabi M. The effect of cognitive behavioural psycho-education on premenstrual syndrome and related symptoms. J Psychiatr Ment Health Nurs. 2013;20(8):705-713. doi: 10.1111/j.13652850.2012.01965.x

21. Pinar G, Colak M, Oksuz E. Premenstrual Syndrome in Turkish college students and its effects on life quality. Sex Reprod Healthc. 2011;2:21-27. doi: 10.1016/j. srhc.2010.10.001

22. Farrokh-Eslamlou H, Oshnouei S, Heshmatian B, Akbari E. Premenstrual syndrome and quality of life in Iranian medical students. Sex Reprod Healthc. 2015;6(1):23-27. doi: 10.1016/j.srhc.2014.06.009

23. Hussein Shehadeh J, Hamdan-Mansour AM. Prevalence and association of premenstrual syndrome and premenstrual dysphoric disorder with academic performance among female university students. Perspect Psychiatr Care. 2018;54(2):176-184. doi: 10.1111/ppc.12219

24. Alemu SM, Habtewold TD, Haile YG. Mental and Reproductive Health Correlates of Academic Performance among Debre Berhan University Female Students, Ethiopia: The Case of Premenstrual Dysphoric Disorder. Biomed Res Int. 2017;9348159. doi: 10.1155/2017/9348159

25. Franik G, Krysta K, Witkowska A, Dudek A, Krzystanek $\mathrm{M}$, Madej P. The impact of sex hormones and metabolic markers on depressive symptoms and cognitive functioning in PCOS patients. Gynecol Endocrinol. 2019:35(11):965-969. doi: 10.1080/09513590.2019.1613359

\section{Authors' Contributions}

FB: Study design and gynecologic examination of all students. Responsible and accountable for the accuracy or integrity of the work.

RA: Editing the manuscript.

CB: Collecting data and analysis of them. 